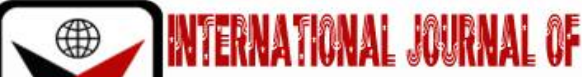

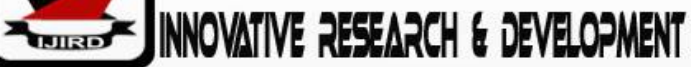

ISSN 2278 - 0211 (Online)

\section{The Sustainable Development Goals and Ghana Development Nexus: An Empirical Assessment}

Isaac Addai

Lecturer, Department of Accounting Studies, University of Education, Winneba, Ghana

\begin{abstract}
:
The 17 Sustainable Development Goals (SDGs) and 169 targets demonstrate the scale and ambition of a vibrant new universal Agenda which seeks to build on the Millennium Development Goals (MDGs) and complete what the MDGs did not achieve. The SDGs seek to realize the human rights of all and to achieve gender equality and the empowerment of all women and girls. The SDGs are integrated, indivisible and balanced the three dimensions of sustainable development namely: the economic, social and environmental. Sections 79 of the SDGs (2015) document obligate Member States to conduct regular and inclusive reviews of progress at the national and subnational levels which must be country-led and country driven. Such reviews should draw on contributions from indigenous peoples, civil society, the private sector and other stakeholders, in line with national circumstances, policies and priorities. The empirical statistical evidence using a micro-level data suggests that respondents (Ghanaians) in 2019 do not consider the SDGs as the panacea for development in Ghana by 2030.The paper therefore recommends that aggressive and pragmatic education on what the SDGs stand for be embarked upon as quickly as possible in Ghana and be sustained for the rest of the years left till 2030.
\end{abstract}

Keywords: Sustainable Development Goals, Panacea, Development, Deliberative event, 2030

\section{Introduction}

The Sustainable Development Goals (SDGs) was developed on the authorities of the Heads of State, Government and High Representatives meeting at United Nations Headquarters in New York from 25 to 27 September 2015 during the Organization celebration of its seventieth anniversary. The SDGs document was titled: Transforming our world: the 2030 Agenda for Sustainable Development, as apost-2015 development Agenda. The 17 SDGs and 169 targets demonstrate the scale and ambition of a vibrant new universal Agenda. It seeks to build on the Millennium Development Goals (MDGs) and complete what the MDGs did not achieve. The SDGs seek to realize the human rights of all and to achieve gender equality and the empowerment of all women and girls. The SDGs are integrated, indivisible and balanced the three dimensions of sustainable development namely: the economic, social and environmental. The SDGs thematic area of concentration and action are: People oriented. The SDGs are determined to end poverty and hunger, in all their forms and dimensions, and to ensure that all human beings can fulfil their potential in dignity and equality and in a healthy environment, planet-friendly. The SDGs are determined to protect the planet from degradation, by promoting sustainable consumption and production, sustainably managing its natural resources and taking urgent action on climate change, so that planet can support the needs of the present and future generations. Promotes Prosperity. The SDGs are determined to ensure that all human beings can enjoy prosperous and fulfilling lives and that economic, social and technological progress occurs in harmony with nature. Nurture Peace the SDGs are determined to foster peaceful, just and inclusive societies which are free from fear and violence stressing that there can be no sustainable development without peace and no peace without sustainable development, global all-inclusiveness through Partnership. The SDGs are determined to mobilize the means required to implement the Agenda through a revitalized Global Partnership for Sustainable Development, based on spirit of strengthened global solidarity, focused in particular on the needs of the poorest and most vulnerable and with the participation of all countries, all stakeholders and all people. The inter linkages and integrated nature of the SDGs are of crucial importance in ensuring that the purpose of the new Agenda is realized. The 17 SDGs of which 169 targets are derived are presented in Table 1. 


\begin{tabular}{|l|}
\hline Goal 1. End poverty in all its forms everywhere \\
\hline $\begin{array}{l}\text { Goal 2. End hunger, achieve food security and improved nutrition and promote sustainable } \\
\text { agriculture }\end{array}$ \\
\hline Goal 3. Ensure healthy lives and promote well-being for all at all ages \\
\hline $\begin{array}{l}\text { Goal 4. Ensure inclusive and equitable quality education and promote lifelong learning } \\
\text { opportunities for all }\end{array}$ \\
\hline Goal 5. Achieve gender equality and empower all women and girls \\
\hline Goal 6. Ensure availability and sustainable management of water and sanitation for all \\
\hline Goal 7 Ensure access to affordable, reliable, sustainable and modern energy for all \\
\hline Goal 8. Promote sustained, inclusive and sustainable economic growth, \\
\hline full and productive employment and decent work for all \\
\hline $\begin{array}{l}\text { Goal 9. Build resilient infrastructure, promote inclusive and sustainable industrialization } \\
\text { and foster innovation }\end{array}$ \\
\hline Goal 10. Reduce inequality within and among countries \\
\hline Goal 11. Make cities and human settlements inclusive, safe, resilient and sustainable \\
\hline Goal 12. Ensure sustainable consumption and production patterns \\
\hline Goal 13. Take urgent action to combat climate change and its impacts \\
\hline $\begin{array}{l}\text { Goal 14. Conserve and sustainably use the oceans, seas and marine resources for sustainable } \\
\text { development }\end{array}$ \\
\hline $\begin{array}{l}\text { Goal 15. Protect, restore and promote sustainable use of terrestrial ecosystems, sustainably } \\
\text { manage forests, combat desertification, and halt and reverse land degradation and halt } \\
\text { biodiversity loss }\end{array}$ \\
\hline $\begin{array}{l}\text { Goal 16. Promote peaceful and inclusive societies for sustainable development, provide } \\
\text { access to justice for all and build effective, accountable and inclusive institutions at all levels }\end{array}$ \\
\hline $\begin{array}{l}\text { Goal 17. Strengthen the means of implementation and revitalize the Global Partnership for } \\
\text { Sustainable Development. }\end{array}$ \\
\hline
\end{tabular}

\section{Table 1: The Sustainable Development Goals}

The SDGs implementation is promoted within the framework of a revitalized Global Partnership for Sustainable Development, supported by the concrete policies and actions outlined in the (2015) Addis Ababa Action Agenda, which is an integral part of the 2030 Agenda for Sustainable Development. The Addis Ababa Action Agenda supports, complements and helps to contextualize the 2030 Agenda's means of implementation targets. It relates to domestic public resources, domestic and international private business and finance, international development cooperation, international trade as an engine for development, debt and debt sustainability, addressing systemic issues and science, technology, innovation and capacity-building, and data, monitoring and follow-up. At the national level, Section 78 of the SDGs encourage all Member States to develop as soon as practicable ambitious national responses to the overall implementation of the Agenda to support the transition from the MDGs to the SDGs and build on existing planning instruments, such as national development and sustainable development strategies, as appropriate. The SDG framework has been questioned by many (Washington 2015; Kopnina 2016). In his discussion of the fallacies of the SDGs, (Easterley2015) argues that the inclusion of weak language and 'escape clauses' creates a situation in which the only thing that all the SDGs promoters could agree on 'was that the SDGs did not actually bind them to anything' (p 323). In many instances, the SDGs fail to combat the global economic and geopolitical systems that create gender and other injustices in the first place (0'Manique and Fourie 2016; Kopnina 2016). Although the 2030 Agenda document (Transforming Our World-TOW) speaks of transformation, it is argued that it will not be possible to achieve a 'win win' when the very systems which create poverty, hunger, inequalities, and unsustainable development are upheld and promoted by nations branding themselves as developed, less developed, and developing nations. These win-wins are not achievable against a sustainable imaginary, given the oxymoron of 'sustainable growth' (Bartlett 1994).

The SDGs could be described as 'an economic imaginary' at the highest levels of government or at best a deliberative event. (Wynne 1996) argued that deliberative events are often framed more around communicating 'propositional knowledge' rather than to generating richer understandings and involvement through lay experiences. The publics in such events are viewed as ill-informed while the experts try to promote 'epistemic asymmetry' between knowledgeable science and lay ignorance (Maranta et al 2003, p153) and seek out that people focused on their own private affairs, 'idiots' and not stakeholders, (Lezaun and Soneryd 2007). Identifying ignorance in others is a way of claiming status for experts. Michael (2012) argues that claims to ignorance may also be a lay strategy, where misbehaviour, absence, refusal, disruption, distraction, irony, challenges the terms of contact with reality. In line with (Scott 2018) postulation that social scientist pursue further investigation of such moments where social action is oriented around things not done or not examined, the paper investigates Ghanaians views towards the implementation of the SDGs as panacea for development in Ghana, with only 11 years remaining in 2019, to achieving all the SDGs targets in 2030using anovel micro-level data. The paper exploits the nature of the data and applies a method from the evaluation statistics to investigate Ghanaians outlook to achieving the SDGs as a tool for development in Ghana. The paper is structured as follows. The next section presents the data used for the analysis. This is followed by the statistical methodology section 3 to evaluate the views of respondents on the SDGs as a panacea for development in Ghana. Section 4 deals with the 
empirical variables definitions and statistical descriptions, while section 5 discusses the empirical results, robustness checks and concludes.

\section{Data}

Given the absence of a national scale data on the monitoring and implementation of the SDGs in Ghana since 2015, this paper collected detailed information to generate a micro-level dataset to investigate the outlook of sampled Ghanaians on whether the SDGs are the panacea for development in Ghana. Students in University of Education, Winneba randomly administer the survey to adults across the regions of Ghana in 2019. A restriction placed on the adults for this paper is that they must have had a formal education. Of the 110 surveys sent out, 107 were completed and returned. A high number were returned because the students prior contact had been made. An adult is defined as a Ghanaian who is 18 years or older and is not a student as at the time of survey. 2 respondents were excluded as there could not provide appropriate responses.

\section{Statistical Methodology}

The paper is primarily concerned with examining the association between whether respondents consider the SDGs as the panacea for development in Ghana and a range of individual characteristics comprising categorical or qualitative variables. A statistical test is conducted to examine the association between whether SDGwas considered as the panacea for development. It is a chi-squared statistical test of independence which is used to test the association between two categorical variables. This test compares actual (or observed) values in a given set of categories to the values expected if a given distributional assumption is satisfied. The SDGs variable takes either a value of 1 or 0 depending on whether an individual considered the SDGs as panacea for development in Ghana or not. To examine whether there is an association between respondents who considered the SDGs as panacea for development in Ghana, across-tabulation of the respondent variable against SDGs is created. If no association exists between respondents consideration and the SDGs measure as the panacea for development in Ghana, then one would expect the proportions of the respondents who considered the SDGs as the panacea for development in Ghana to be the same as the respondents who do not consider the SDGs measure as the panacea for development in Ghana, in the overall sample. The goodness-of-fit test focuses on the differences between the observed proportions (or frequencies) and the expected proportions (or frequencies). Large differences between observed and expected frequencies cast doubt on the 'null hypothesis' that there is no association between respondents who considered the SDGs measure as the panacea for development in Ghana. A chi-squared test provides the statistical basis for testing whether the large differences observed are statistically significant or not, using a conventionally defined critical value. This is usually referred to as a goodness-of-fit test since it attempts to test the hypothesis that an observed frequency distribution fits some claimed distribution. The test statistic for the goodness-of-fit is denoted by

$$
\chi^{2}=\sum_{i=1}^{n} \sum_{j=1}^{m}\left[f_{i j}-e_{i j}\right]^{2} \div e_{i j}(1)
$$

Where $f_{i j}=$ observed frequency for category $i j$, and $e_{i j}=$ expected frequency for category $i j$, based on the assumption of independence. The test statistic is distributed as chi-squared with $(n-1) \times(m-1)$ degrees of freedom (provided that the expected frequencies are five or more for all categories under consideration). The null hypothesis being tested here is that there is no association between the two variables of interest. If $\chi^{2}>\chi_{\alpha}$ then one can reject the null hypothesis, where $\alpha$ is the level of statistical significance. Rather than report values of the chi-squared test and critical values, this paper use prob-value to reject the nullhypothesis. The lower the prob-value the lower the probability that one is wrongly rejecting the null hypothesis, therefore the more confident we are that the inferences are statistically reliable. Using the conventional 95 percent confidence interval, the paper infers that froma prob-value above 0.05 one can safely reject the null hypothesis of independence between the variables used in the crosstabulations.

\section{Empirical Variables}

Respondents considering the SDGs as the panacea for development in Ghana is the key concern. The explanatory variables used for the determination are now described in turn in Table 2.

\begin{tabular}{|c|c|c|c|}
\hline Variable & Description & Mean & Standard Deviation \\
\hline resps & Respondents = 1 if male, = 0 if female & 0.7619048 & 0.4279605 \\
\hline devsdg & $\begin{array}{c}\text { SDGs: A dummy =1 if respondent } \\
\text { consider the SDGs as panacea of } \\
\text { development in Ghana, 0 if otherwise }\end{array}$ & 0.1714286 & 0.3786906 \\
\hline sdgmdg & $\begin{array}{c}\text { If respondent remembers the MDGs= 0 if } \\
\text { otherwise }\end{array}$ & 0.1047619 & 0.3077152 \\
\hline Total & $\begin{array}{c}\text { 25 Females } \\
80 \text { males }\end{array}$ & & \\
\hline
\end{tabular}

Table 2: Description of Variables 
The expectation is that: $\partial \mathrm{resps} / \mathrm{devsdg}>0$, which interprets to mean that, respondents considered the SDGs as the panacea for development in Ghana by 2030 and it is hypothesised that:

- $\mathrm{H}_{0}$. Respondents considered the SDGs as the panacea for development in Ghana by 2030.

- $\mathrm{H}_{1}$. Respondents do not consider the SDGs as the panacea for development in Ghana by 2030.

\section{Discussion of Empirical Results and Conclusion}

A prob-value generated from the STATA 14 statistical software was Pearson chi2(1) $1.0862 \operatorname{Pr}=0.297 .10$ percent of the sampled respondents do remember the MDGs. The lower the prob-value the lower the probability that we are wrongly rejecting the null hypothesis, therefore the more confident we are that the inferences are statistically reliable. Using the conventional 95 per cent confidence interval, an inference from a prob-value below 0.05 accepts the null hypothesis that respondents consider the SDGs as the panacea of development in Ghana. A higher prob-value of 0.30 have rejected the null hypothesis at the conventional 95 per cent confidence interval by accepting the alternative hypothesis that respondents (Ghanaians) do not consider the SDGs as the panacea for development in Ghana by 2030 . Sections 79 of the SDGs (2015) document obligate Member States to conduct regular and inclusive reviews of progress at the national and subnational levels which must be country-led and country driven. Such reviews should draw on contributions from indigenous peoples, civil society, the private sector and other stakeholders, in line with national circumstances, policies and priorities. From a public policy perspective, a rejection of the SDGs as a panacea for development in Ghana in 2019, by 2030 poses a bigger socio-economic-environmental issue which need to be addresses vigorously by the government of Ghana, a signatory to the SDGs pact. Personal trust and belief in the SDGs are essential to carry all aboard to be in line with the SDGs admonishing that 'States are expected to take bold and transformative steps which are urgently needed to shift the world on to a sustainable and resilient path and pledged that no citizen will be left behind'. Rejecting the SDGs ideas and programmes as panacea for development in Ghana by 2030 by respondents in Ghana could be attributed to the fact that educating the citizenry on the SDGs and courting their involvement by the central government, regional, metropolitan and district assemblies have not been extensive enough. The paper therefore recommends that aggressive and pragmatic education on what the SDGs stand for be embarked upon as quickly as possible in Ghana and be sustained during the rest of the years left till 2030.

\section{Conflicts of Interest}

The author declares no conflicts of interest regarding the publication of this paper.

\section{References}

i. Bartlett A (1994) Reflections on sustainability, population growth and the environment. Population Environment, 16:5-35.

ii. Easterly W (2015). The trouble with the sustainable development goals. Current History 114(775):322-324.

iii. Kopnina, H. (2016). The victims of unsustainability: a challenge to sustainable development goals. International Journal of Sustainable Development and World Ecology, 23(2):113-121

iv. Lezaun, J. \& Soneryd, L. (2007). Consulting citizens: Technologies of elicitation and the mobility of publics. Public Understanding of Science, 16:279-297.

v. Maranta, A. Guggenheim, Gisler, M. P., Pohl, C. (2003). The Reality of Experts and the Imagined Lay Person, Act a Sociologica, 46(2):150-165.

vi. Michael, M. (2012). 'What are we busy doing?': Engaging the Idiot. Science, Technology and Human Values, 37(5):582-544.

vii. O'Manique C, \& Fourie P (2016). Affirming our world: gender justice, social reproduction, and the sustainable development goals. Development, 59(1-2):121-126.

viii. Scott, S. (2018). A sociology of nothing: understanding the unmarked. Sociology, 52(1):3-19.

ix. UN General Assembly (2015). Resolution adopted by the General Assembly on 25 September 2015: 70/1. Transforming our world: the 2030 Agenda for Sustainable Development Geneva, United Nations.

x. Washington, H. (2015). Demystifying sustainability: towards real solutions. Routledge, London.

xi. Wynne, B.E. (1996). May the sheep safely graze? A reflexive view of the expert-lay knowledge divide. In Risk, environment and modernity: towards a new ecology ed. London: Sage. 